Table A1: Average hit and false alarm probabilities for Experiments 1-5

\title{
Experimental Conditions
}

\begin{tabular}{|c|c|c|c|c|c|c|}
\hline \multirow[t]{2}{*}{ Experiment 1} & \multicolumn{4}{|c|}{ Exposure duration and target context } & & \\
\hline & $\begin{array}{l}25 \mathrm{~ms} \text {, } \\
\text { blocked }\end{array}$ & $\begin{array}{l}250 \mathrm{~ms} \\
\text { blocked }\end{array}$ & $\begin{array}{l}25 \mathrm{~ms}, \\
\text { random }\end{array}$ & $\begin{array}{l}250 \mathrm{~ms}, \\
\text { random }\end{array}$ & & \\
\hline super. & $.96, .09$ & $.91, .04$ & $.89, .05$ & $.91, .07$ & & \\
\hline basic & $.93, .05$ & $.97, .08$ & $.94, .07$ & $.96, .07$ & & \\
\hline subor. & $.78, .12$ & $.77, .11$ & $.79, .10$ & $.77, .11$ & & \\
\hline \multirow[t]{2}{*}{ Experiment 2} & \multicolumn{6}{|c|}{ Mask SOA } \\
\hline & $25 \mathrm{~ms}$ & $33 \mathrm{~ms}$ & $50 \mathrm{~ms}$ & $67 \mathrm{~ms}$ & $125 \mathrm{~ms}$ & $250 \mathrm{~ms}$ \\
\hline super. & $.80, .16$ & $.88, .10$ & $.91, .09$ & $.92, .08$ & $.91, .08$ & $.94, .07$ \\
\hline basic & $.71, .15$ & $.81, .13$ & $.92, .10$ & $.90, .07$ & $.93, .07$ & $.94, .05$ \\
\hline \multirow[t]{2}{*}{ Experiment 3} & \multicolumn{5}{|c|}{ Mask SOA } & \\
\hline & $25 \mathrm{~ms}$ & $33 \mathrm{~ms}$ & $50 \mathrm{~ms}$ & $75 \mathrm{~ms}$ & $125 \mathrm{~ms}$ & \\
\hline super. & $.75, .18$ & $.91, .09$ & $.88, .09$ & $.90, .08$ & $.87, .07$ & \\
\hline basic & $.60, .19$ & $.83, .19$ & $.84, .15$ & $.89, .17$ & $.86, .12$ & \\
\hline \multirow[t]{2}{*}{ Experiment 4} & \multicolumn{2}{|c|}{ Target context } & & & & \\
\hline & blocked & random & & & & \\
\hline super. & $.90, .11$ & $.87, .09$ & & & & \\
\hline basic & $.93, .12$ & $.91, .13$ & & & & \\
\hline subor. & $.82, .21$ & $.82, .25$ & & & & \\
\hline \multirow[t]{2}{*}{ Experiment 5} & \multicolumn{5}{|c|}{ Prime type } & \\
\hline & baseline & $\begin{array}{l}\text { super. } \\
\text { match }\end{array}$ & $\begin{array}{c}\text { super. } \\
\text { nonmatch }\end{array}$ & $\begin{array}{l}\text { basic } \\
\text { match }\end{array}$ & $\begin{array}{c}\text { basic } \\
\text { nonmatch }\end{array}$ & \\
\hline super. & $.90, .07$ & $.94, .05$ & $.92, .11$ & $.94, .05$ & $.93, .08$ & \\
\hline basic & $.94, .13$ & $.95, .13$ & $.89, .06$ & $.94, .14$ & $.91, .08$ & \\
\hline
\end{tabular}

